\title{
A recurrent mutation, ala391glu, in the transmembrane region of FGFR3 causes Crouzon syndrome and acanthosis nigricans
}

\author{
D Wilkes, P Rutland, L J Pulleyn, W Reardon, C Moss, J P Ellis, R M Winter, S Malcolm
}

\begin{abstract}
Mutations in the fibroblast growth factor receptor 2 (FGFR2) gene have previously been identified in Crouzon syndrome, an autosomal dominant condition involving premature fusion of the cranial sutures. Several different missense and other mutations have been identified in Crouzon syndrome patients, clustering around the third immunoglobulin-like domain. We report here the identification of a mutation in the transmembrane region of FGFR3, common to three unrelated patients with classical Crouzon syndrome and acanthosis nigricans, a dermatological condition associated with thickening and abnormal pigmentation of the skin. The mutation within the FGFR3 transcript was determined by direct sequencing as a specific geg to gag transversion, resulting in an amino acid substitution ala391glu within the transmembrane region.

( $($ Med Genet 1996;33:744-748)
\end{abstract}

Keywords: Crouzon syndrome; acanthosis nigricans; fibroblast growth factor receptor 3 (FGFR3).

Mothercare Unit of Clinical Genetics and Fetal Medicine and Molecular Genetics Unit, Institute of Child Health, 30 Guilford Street, London WC1N 1EH,UK

D Wilkes

$P$ Rutland

L J Pulleyn

W Reardon

R M Winter

S Malcolm

Department of

Dermatology,

Birmingham

Children's Hospital, Ladywood,

Birmingham B16 8ET,

UK

C Moss

Department of Dermatology, Princess Margaret Hospital, Okus Road, Swindon, Okus Road, Swind
Wilts SN1 4JU,UK J P Ellis

Correspondence to: Dr Reardon.

Received 4 March 1996 Revised version accepted for publication 28 May 1996
Several clinically distinct monogenic disorders present with craniosynostosis, the premature fusion of the skull bone sutures. ${ }^{12}$ Initially delineated purely on clinical grounds, several reports over the last year have identified the mutational basis of the phenotypes and posed the resultant malformations arise. ${ }^{3}$ Initially described in Crouzon syndrome, mutations at the fibroblast growth factor receptor 2 (FGFR2) locus on chromosome 10 have since been identified in Apert and Jackson-Weiss syndromes. ${ }^{4-6}$

A mutation in the related gene on chromosome 8, FGFR1, has been characterised in Pfeiffer syndrome, ${ }^{7}$ but locus heterogeneity in this syndrome was established with the observation of Pfeiffer syndrome cases having mutations at the FGFR2 locus. ${ }^{8-11}$ More than three such mutations, all resulting in the substitution of cys342, have been identified in both Crouzon and Pfeiffer syndrome cases and the factors governing the development of these clinically distinct malformation syndromes, arising from the same initial mutation, remain unclear. ${ }^{12}$ Gorry et $a l^{13}$ have cited an identical mutation (ala344gly) in FGFR2 in Crouzon new questions as to the mechanisms by which and Jackson-Weiss syndromes as an example of the same phenomenon.

Crouzon syndrome, which is clinically differentiated from these other syndromic forms of craniosynostosis by the degree of proptosis, maxillary hypoplasia, and the absence of limb malformations, has now been associated with over 30 mutations at the FGFR2 locus, missense, splice site, and small in frame deletions. ${ }^{4{ }^{13-15}}$ Mutations are located in both the first and second half of the third immunoglobulin-like domain, and the nonrandom pattern of mutations has been discussed elsewhere. ${ }^{12}$ Although the range of FGFR2 mutations associated with Crouzon syndrome has been broad, the original linkage data showed no evidence of heterogeneity. ${ }^{1617}$ To date, analysis of the FGFR2 locus has identified mutations in approximately $66 \%$ of our Crouzon syndrome cohort of 70 patients, none of whom had acanthosis nigricans.

One of the less common associations seen in a subgroup of patients with Crouzon syndrome is acanthosis nigricans. This velvety hyperplasia of the skin, with accentuation of skin markings and hyperpigmentation, is usually found on the neck, axillae, and other flexural regions of the body, but acanthosis nigricans is, in general, recognised to be clinically heterogeneous. Although uncommon, the association with Crouzon syndrome is clear, 11 such cases having been identified by Koizumi et al. ${ }^{18}$ These authors drew attention to some atypical features of the Crouzon associated acanthosis nigricans, specifically the early onset of the pigmentation and the unusual distribution of the affected skin, particularly involving the perioral region.

Mutations within FGFR3 have been identified in discrete skeletal dysplasias. Four such conditions have now been causatively associated with FGFR3 mutations: achondroplasia, in which virtually all mutations are in the transmembrane region of the receptor, ${ }^{19-21}$ hypochondroplasia, in which there are two mutations in the tyrosine kinase domain, ${ }^{22}{ }^{23}$ and thanatophoric dysplasia types I and II (TDI and II). TDI, in which the femora are curved, has been described in association with missense mutations involving creation of a cysteine in the linker region between immunoglobulin-like domains 2 and $3^{24}$ and read through mutations of the stop codon. ${ }^{26}$ Type II, characterised by relatively long and straight femora, has been described in association with a tyrosine kinase domain mutation 

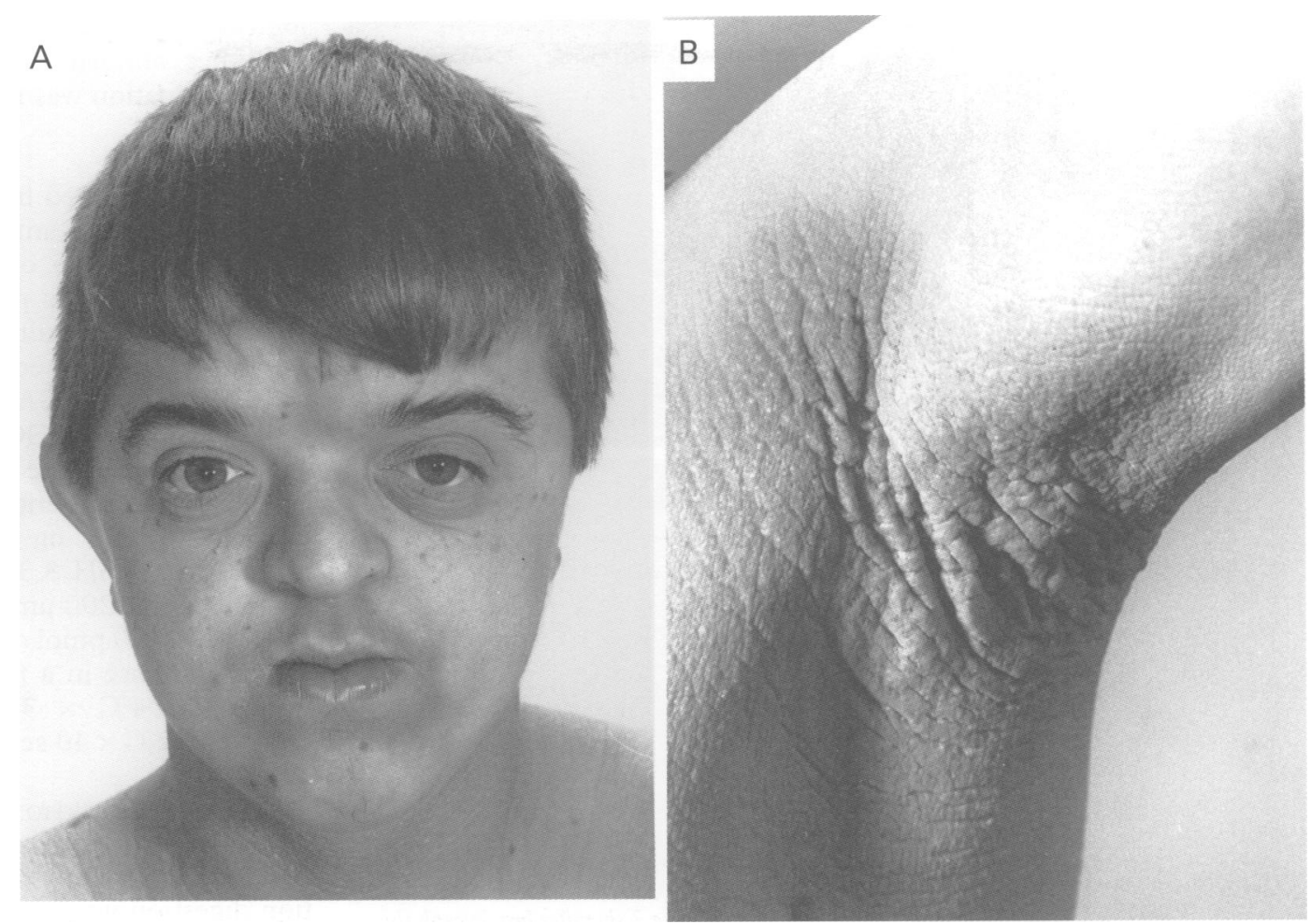

Figure 1 Postoperative appearance of case 1. Note the mild facial asymmetry and perioral acanthosis nigricans $(A)$ and the flexural skin thickening and acanthosis nigricans (B). (All photographs reproduced with permission.)

(K650E) of FGFR3. ${ }^{24}$ As both types may be associated with the severe skull malformation, clover leaf skull, TDI and II represent evidence that FGFR3 mutations may also have craniosynostosis clinically. We now extend the association between FGFR3 mutations and craniosynostosis by reporting a single specific mutation, ala391glu, in the transmembrane region of FGFR3 in three unrelated patients with Crouzon syndrome and acanthosis nigricans. This is only 11 amino acids away, within the transmembrane domain, from the predominant mutation causing achondroplasia.

\section{Patients and methods}

CASE 1

This male patient (fig 1) was born to clinically normal parents following a normal pregnancy and delivery. Birth weight, head circumference,
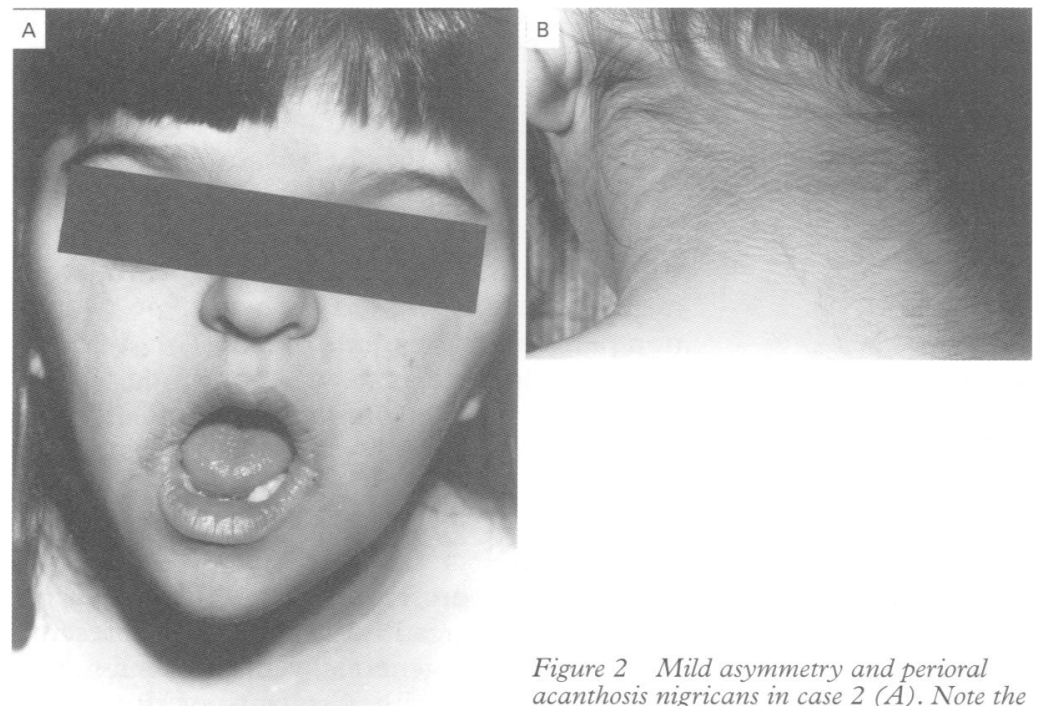

Figure 2 Mild asymmetry and perioral acanthosis nigricans in case $2(A)$. Note the acanthosis nigricans over the neck (B). and other clinical parameters were normal. Proptosis and skull malformation were evident from birth and craniosynostosis was confirmed radiologically. Motor and intellectual development have been normal and the craniosynostosis has been managed surgically. At the age of 14 years, he was referred to a dermatologist (CM) with a history of dry skin on the face since the age of 9. Clinical examination showed extensive acanthosis nigricans of the axilla, neck, and, to a lesser extent, the groin. The periorbital and perioral skin was prominently affected but there was no palmoplantar or mucosal involvement. There was generalised skin thickening, particularly over the trunk. In addition several small, warty acanthomas were noted, as were several melanocytic naevi on the face and upper trunk.

CASE 2

This female patient was born to clinically normal parents (fig 2). The early clinical course was dominated by problems with feeding and failure to thrive. Incomplete choanal atresia led to associated respiratory difficulties. Her head circumference was on the 50th centile, disproportionately large for her height and weight, which were both below the 3 rd centile. There was proptosis clinically and skull $x$ ray confirmed premature bicoronal synostosis at the age of 8 months. There was midface hypoplasia and surgical correction of the craniofacial malformations was performed at the age of 10 months. Motor and intellectual development were normal. Reviewed dermatologically at the age of 6 years (JPE), there was a notable degree of thickening of the skin around the neck and fossae. Velvety thickening and hyperpigmentation, characteristic of acanthosis nigricans, were seen on the neck, axillae, antecu- 

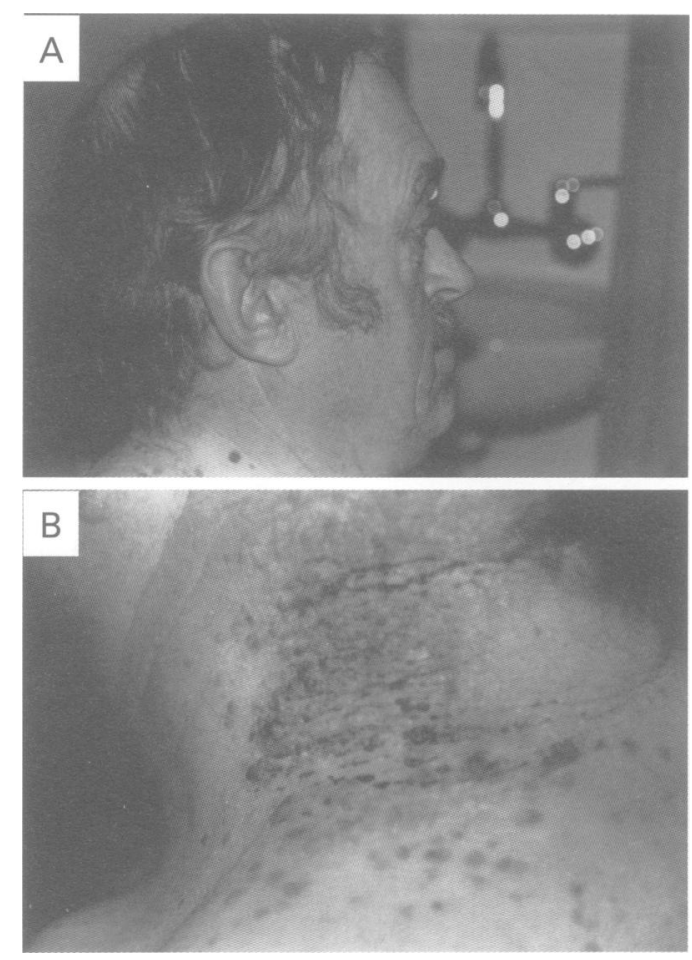

Figure 3 Lateral view of case 3 showing brachycephaly and maxillary hypoplasia. Note the warty acanthomas over the lower neck $(A)$ and severe acanthosis nigricans over the neck (B).

bital fossae, and around the umbilicus and the angles of the mouth.

CASE 3

This 61 year old man was referred for genetic counselling for Crouzon syndrome (fig 3 ). His daughter was also similarly affected with acanthosis nigricans. The family history was otherwise non-contributory. His skull shape had been abnormal from early childhood and surgical reconstruction of his orbits had been undertaken at the age of 18 years to reduce his proptosis. Skull $x$ ray examination showed brachycephaly, hypertelorism, and hypoplasia of the maxillary bones. He reported the presence of acanthosis nigricans from "early childhood". Clinical examination showed typical verrucous, hyperpigmented lesions over his neck, axillae, and groin. There was also hyperpigmentation periorbitally and periorally, in addition to generalised skin thickening and extensive distribution of warty acanthomas over his back. Being significantly older than cases 1 and 2, the progression of his dermato-

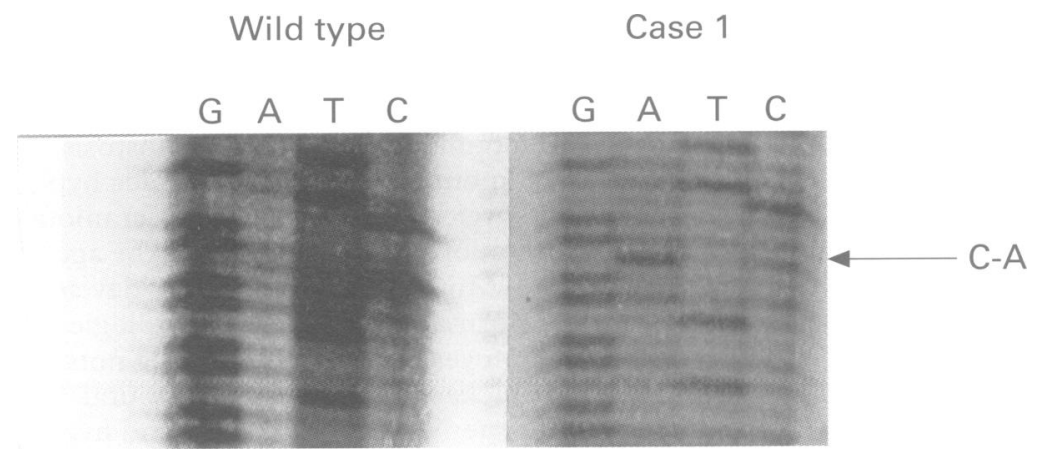

Figure 4 Sequencing of the transmembrane region of FGFR3. Track 1, wild type. Track 2, case 1. logical involvement was striking. There were no other abnormalities and a recent blood sugar evaluation was normal.

\section{PCR ANALYSIS}

DNA was extracted from lymphocytes by salting out. ${ }^{27}$ Primers amplifying the entire transmembrane domain of FGFR3 from genomic DNA were used as previously published. ${ }^{19} \mathrm{~A}$ 164 bp product results.

The primer sequences 5'AGGAGCTGGTGGAGGCTGA-3' and 5'BioGGAGATCTTGTGCACGGTGG-3' were designed to amplify the entire transmembrane domain of FGFR3 from genomic DNA. PCR conditions were $200 \mathrm{ng}$ of genomic DNA, 10 mmol. $1^{-1}$ Tris, $\mathrm{pH} 8.3,1.5 \mathrm{mmol}^{-1} \mathrm{MgCl}^{-1} 50$ mmol. $1^{-1} \mathrm{KCl}, 200 \mu \mathrm{mol}^{-1} \mathrm{l}^{-1} \mathrm{dNTP}, 0.7 \mu \mathrm{mol} \mathrm{l}^{-1}$ $\alpha^{32} \mathrm{P}$-dCTP, $50 \mathrm{pmol}$ of each primer, and $0.5 \mathrm{U}$ Taq polymerase in a final volume of $50 \mu \mathrm{l}: 30$ cycles of $94^{\circ} \mathrm{C} \times 30$ seconds, $64^{\circ} \mathrm{C} \times 30$ seconds, $72^{\circ} \mathrm{C} \times 40$ seconds.

\section{RESTRICTION DIGESTION}

PCR products were purified by phenol/ chloroform ethanol precipitation and restriction digestion was performed according to the manufacturer's specifications (New England Biolabs). Resolution of fragment products was performed on a $3 \%$ agarose gel.

DNA SEQUENCING

PCR products were sequenced directly by including a single $5^{\prime}$ biotinylated primer in the PCR reaction. PCR products were then captured and immobilised to Dynabeads M280 streptavidin (Dynal). This was followed by denaturation using $0.15 \mathrm{~mol} / 1 \mathrm{NaOH}^{28}$ and sequencing using $\alpha^{35} S$-dATP and the Sequenase kit (Amersham).

\section{Results}

Sequencing showed a point mutation in the patients compared to the normal control and published sequence (fig 4). The C-A mutation was predicted to destroy a $A c i$ restriction site. The normal fragment sizes generated following Aci I digestion of the $164 \mathrm{bp}$ PCR fragment is $17 \mathrm{bp}, 24 \mathrm{bp}, 57 \mathrm{bp}$, and $66 \mathrm{bp}$ while fragment sizes generated following restriction of PCR products from affected chromosomes of patients were predicted to be $24 \mathrm{bp}, 57 \mathrm{bp}$, and $83 \mathrm{bp}$. Following PCR amplification of the affected subjects, products were digested with $A c i$ I and the resulting fragments resolved on a $3 \%$ agarose gel (fig 5). All three affected subjects showed the $83 \mathrm{bp}$ fragment while the normal controls showed the wild type restriction pattern. The parents of case 1 showed the normal wild type pattern, confirming the de novo nature of his mutation. Similarly, the affected daughter of case 3 also shares his mutation.

\section{Discussion}

The data we present confirm that Crouzon syndrome with acanthosis nigricans represents a clinically and genetically distinct subgroup among patients with Crouzon syndrome, as reported by Myers et al. ${ }^{29}$ Together these data, 


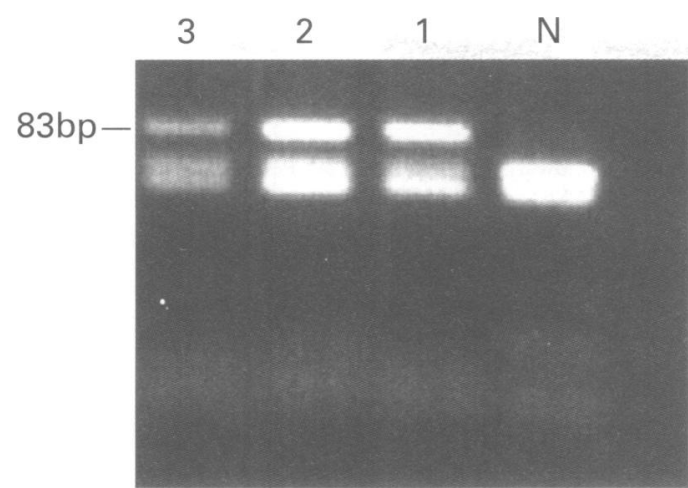

Figure 5 Resolution of fragments following PCR amplification and restriction digestion with AciI. N: normal, 1: case 1, 2: case 2, 3: case 3.

in a total of seven patients, all showing acanthosis nigricans in addition to Crouzon features, represent the first evidence of locus heterogeneity within the Crouzon syndrome patient group. That the mutation is causative is confirmed by the de novo observation in case 1 and the identification of the identical mutation in the affected daughter of case 3.

The amino acid change, which results in the substitution of a charged for a non-charged residue, is only 11 amino acids away from the predominant mutation (G380R), in the transmembrane region of FGFR3, found in achondroplasia. As both mutations involve creation of an additional positive charge, correct insertion of the molecule into the membrane is likely to be hindered.

FGFR3 and FGFR2 have quite different patterns of expression during organogenesis, ${ }^{30}$ so it is somewhat surprising that mutations in both genes should give rise to such similar effects on the sutures of the skull. It further means that the explanation of the mode of action should probably include other factors whose pattern of expression reflects more closely the tissues affected. Possible candidates are the proteoglycans, which are required as a third component in the activation of FGFRs by FGFs, and whose composition is likely to vary in different types of cartilage. ${ }^{31}$

In general FGFR3 the expression pattern is more restricted than that of FGFR1 and FGFR2. The most prominent expression is in prebone cartilage rudiments of all bones including flat bones of the skull and later in development in resting cartilage, a pattern which correlates well with the skeletal dysplasias resulting from several FGFR3 mutations, but is more difficult to explain in cases with only cranial involvement. As with FGFR1 and 2 , the second half of the third immunoglobulin-like loop is encoded by one of two alternatively spliced exons. The IIIb form, equivalent to KGFR in FGFR2, is expressed in mouse skin and epidermal keratinocytes so it seems likely that this splice form may be responsible for the acanthosis nigricans.

As a clinical sign, acanthosis nigricans is frequently observed with syndromes of insulin resistance, such as Berardinelli lipodystrophy and mutation involving the insulin receptor gene. Significantly, there is no evidence of disturbed glucose metabolism in any of our cases.
In keeping with the observations of Koizumi et $a l^{18}$ in Crouzon syndrome related acanthosis nigricans, the skin stigmata in our three cases showed the atypical age of onset and unusual distribution, including perioral involvement, which seemingly characterises this condition.

The phenotype is still unexpected and it remains to be seen whether other Crouzon cases, without the acanthosis nigricans, will be found to have FGFR3 mutations or whether, as might be predicted, the outstanding Crouzon related mutations are located elsewhere in the FGFR2 gene.

This work was funded by the Wellcome Trust and the Medical Research Council.

1 Cohen MM Jr. Craniosynostosis: diagnosis, evaluation and management. New York: Raven, 1986.

Winter RM, Baraitser M. The London dysmorphology database. Oxford: Oxford University Press, 1994

3 Reardon W, Winter RM. The molecular pathology of syndromic craniosynostosis Mol Med Today 1995; 11:432-7.

4 Reardon W, Winter RM, Rutland P, Pulleyn LJ, Jones BM, Malcolm S. Mutations in the fibroblast growth factor receptor 2 gene cause Crouzon syndrome. Nature Genet 1994;8:98-103.

5 Wilkie AOM, Slaney SF, Oldridge M, et al. Apert syndrome results from localized mutations of FGFR2 and is allelic with Crouzon syndrome. Nature Genet 1995;9:165-72.

6 Jabs EW, Li X, Scott AF, et al. Jackson-Weiss and Crouzon syndromes are allelic with mutations in fibroblast growth syndromes are allelic with mutations in fibrob
factor receptor 2. Nature Genet 1994;8:275-84.

7 Muenke M, Schell U, Hehr A, et al. A common mutation in the fibroblast growth factor receptor 1 gene in Pfeiffer syndrome. Nature Genet 1994;8:269-73.

8 Rutland P, Pulleyn LJ, Reardon W, et al. Identical mutation in the FGFR2 gene cause both Pfeiffer and Crouzon syndrome phenotypes. Nature Genet 1995;9:173-6.

9 Schell U, Hehr A, Feldman GJ, et al. Mutations in FGFR1 and FGFR2 cause familial and sporadic Pfeiffer syndrome. Hum Molec Genet 1995;4:323-8.

10 Lajeunie E, Ma HW, Bonaventure J, Munnich A, Le Merrer $\mathrm{M}$, Renier D. FGFR2 mutations in Pfeiffer syndrome. Nature Genet 1995;9:108.

11 Park W, Meyers GA, Li X, et al. Novel FGFR2 mutations in Crouzon and Jackson-Weiss syndromes show allelic heterogeneity and phenotypic variability. Hum Molec Gene 1995;4:1229-33.

12 Malcolm S, Reardon W. Fibroblast growth factor receptor 2 mutations in craniosynostosis. Proc Natl Acad Sci USA (in press).

13 Gorry MG, Preston RA, White GJ, et al. Crouzon syndrome: mutations in two spliceoforms of FGFR2 and a common point mutation shared with Jackson-Weiss syndrome. Hum Molec Genet 1995;4:1387-90.

14 Oldridge M, Wilkie AOM, Slaney SF, et al. Mutations in the third immunoglobulin domain of the fibroblast growth factor receptor-2 gene in Crouzon syndrome. Hum Molec Genet 1995;4:1077-82.

$15 \mathrm{Li} \mathrm{X}$, Park W, Pyeritz RE, Jabs EW. Effect on splicing of a silent FGFR2 mutation in Crouzon syndrome. Nature Genet 1995;9:232-3.

16 Preston RA, Post JC, Keats BJB, et al. A gene for Crouzon craniofacial dysostosis maps to the long arm of chromosome 10. Nature Genet 1994;7:149-53.

$17 \mathrm{Li} \mathrm{X}$, Lewanda AF, Eluma F, et al. Two craniosynostotic syndrome loci, Crouzon and Jackson-Weiss, map to chromosome 10q23-q26. Genomics 1994;23:418-24.

18 Koizumi H, Tomoyori T, Sato KC, Ohkawara A. An association of acanthosis nigricans and Crouzon syndrome. $\mathcal{F}$ Dermatol 1992;19:122-6.

19 Shiang R, Thompson LM, Zhu YZ, et al. Mutations in the transmembrane domain of FGFR3 cause the most common genetic form of dwarfism, achondroplasia. Cell 1994;8:335-42.

20 Rousseau F, Bonaventure J, Legeai-Mallet L, et al. Mutations in the gene encoding fibroblast growth factor receptor-3 in achondroplasia. Nature 1994;371:252-4.

21 Bellus GA, Hefferon TW, de Luna RIO, et al. Achondroplasia is defined by recurrent G380R mutations of plasia is defined by recurrent G380R

22 Bellus GA, McIntosh I, Smith AE, et al. A recurrent mutation in the tyrosine kinase domain of fibroblast growth factor receptor 3 causes hypochondroplasia. Nature Genet 1995; 10:357-9.

23 Bellus GA, Sazabo JK, McIntosh L, et al. Hypochondroplasia: a second mutation of fibroblast growth factor receptor 3 (FGFR3) at nucleotide 1620. Am $\mathcal{f}$ Hum Genet 1955;57:A47.

24 Tavormina PL, Shiang R, Thompson LM, et al. Thanatophoric dysplasia (types I and II) caused by distinct mutations in fibroblast growth factor receptor 3. Nature Genet 1995;9:321-30. 
25 Tavormina PL, Rimoin DL, Cohn DH, Zhu Y, Shiang R, Wasmuth JJ. Another mutation that results in the substitution of an unpaired cysteine residue in the extracellular domain of FGFR3 in thanatophoric dysplasia type I. Hum Molec Genet 1995;4:2175-7.

26 Rousseau F, Saugieer P, LeMerrer M, et al. Stop codon FGFR3 mutations in thanatophoric dwarfism type I. Nature Genet 1995;10:11-12.

27 Miller SA, Dykes DD, Polesky HF. A simple salting out procedure for extracting DNA from human nucleated cells. Nucleic Acids Res 1988;16:1215.

28 Thein SL, Hinton J. A simple and rapid method of direct sequencing using Dynabeads. Br f Haematol 1991;79: 113-15.

29 Myers GA, Orlow SJ, Munro IR, Prylepa A, Jabs EW. Fibroblast growth factor receptor 3 (FGFR3) transmembrane mutation in Crouzon syndrome with acanthosis nigricans. Nature Genet 1995;11:462-4

30 Peters K, Ornitz DM, Werner S, Williams L. Unique expression pattern of FGF receptor 3 gene during mouse expression pattern of FGF receptor 3 gen
organogenisis. Dev Biol 1995;155:423-30.

31 Schlessinger J, Lax I, Lemmon M. Regulation of growth factor activation by proteoglycans: what is the role of low affinity receptors. Cell 1995;83:357-60. 